\title{
Usher syndrome type IV: clinically and molecularly confirmed by novel ARSG variants
}

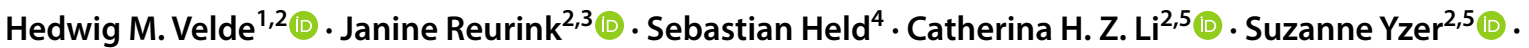 \\ Jaap Oostrik ${ }^{1,2}$ - Jack Weeda ${ }^{5} \cdot$ Lonneke Haer-Wigman $^{2,3}$ (D) Helger G. Yntema ${ }^{2,3}$ (1) $\cdot$ Susanne Roosing ${ }^{2,3}$ (1)

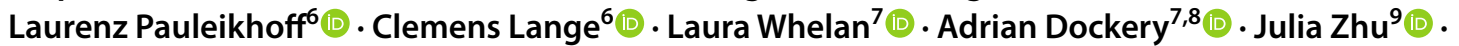

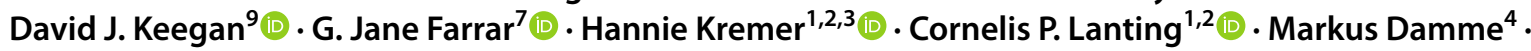 \\ Ronald J. E. Pennings ${ }^{1,2}$ (1)
}

Received: 23 November 2021 / Accepted: 10 February 2022 / Published online: 28 February 2022

(c) The Author(s) 2022

\begin{abstract}
Usher syndrome (USH) is an autosomal recessively inherited disease characterized by sensorineural hearing loss (SNHL) and retinitis pigmentosa (RP) with or without vestibular dysfunction. It is highly heterogeneous both clinically and genetically. Recently, variants in the arylsulfatase G $(A R S G)$ gene have been reported to underlie USH type IV. This distinct type of USH is characterized by late-onset RP with predominantly pericentral and macular changes, and late onset SNHL without vestibular dysfunction. In this study, we describe the USH type IV phenotype in three unrelated subjects. We identified three novel pathogenic variants, two novel likely pathogenic variants, and one previously described pathogenic variant in ARSG. Functional experiments indicated a loss of sulfatase activity of the mutant proteins. Our findings confirm that ARSG variants cause the newly defined USH type IV and support the proposed extension of the phenotypic USH classification.
\end{abstract}

$\begin{array}{ll}\text { Abbreviations } \\ \text { ARSG } & \text { Arylsulfatase G } \\ \text { bp } & \text { Base pair } \\ \text { dB HL } & \text { Decibel hearing level } \\ \text { ERG } & \text { Electroretinography } \\ \text { ER } & \text { Endoplasmic reticulum } \\ \text { HL } & \text { Hearing loss } \\ \text { KO } & \text { Knockout } \\ \text { OCT } & \text { Optical coherence tomography } \\ \text { pNCS } & \text { P-nitrocatechol sulfate } \\ \text { PTA } & \text { Pure-tone average } \\ \text { OD/OS } & \text { Right/left eye } \\ \text { RP } & \text { Retinitis pigmentosa } \\ \text { SNHL } & \text { Sensorineural hearing loss } \\ \text { USH } & \text { Usher syndrome } \\ \text { WT } & \text { Wild type }\end{array}$

Cris P. Lanting, Hannie Kremer, and Markus Damme contributed equally.

Ronald J. E. Pennings

Ronald.Pennings@radboudumc.nl

\section{Introduction}

Usher syndrome (USH) is an autosomal recessively inherited disease characterized by sensorineural hearing loss (SNHL) and retinitis pigmentosa (RP) with or without vestibular dysfunction. It is the leading cause of inherited deaf-blindness with an estimated prevalence of 3-17 per 100,000 individuals (Boughman et al. 1983; Grondahl 1987; Hallgren 1959; Hope et al. 1997; Kimberling et al. 2010; Rosenberg et al. 1997; Spandau and Rohrschneider 2002). USH is highly heterogeneous from both a clinical and a genetic perspective. Understanding the different genotypes and associated phenotypes is essential for genetic counseling and informing patients about their prognosis. It is also necessary to evaluate the efficacy of future therapies and to select patients that are eligible for such therapies.

Previously, three clinical types of USH were distinguished based on the age of onset, severity, and progression of symptoms (Davenport and Omenn 1977; Smith et al. 1994). USH type I is characterized by severe to profound congenital SNHL, the onset of RP in the first decade of life, and vestibular areflexia (Nisenbaum et al. 2021). USH type II is the most common type of the disease, with moderate to severe congenital SNHL and onset of RP in the second 
decade of life or later (Nisenbaum et al. 2021; Tsilou et al. 2002). Vestibular function was previously considered unaffected. However, recent studies have also identified vestibular defects in USH II patients (Magliulo et al. 2017; Stemerdink et al. 2021; Wafa et al. 2021). USH type III displays variable progressive SNHL with the age of onset usually in the first decade of life, variable onset of RP, typically by the second decade of life, and variable vestibular function (Geng et al. 2017; Nisenbaum et al. 2021). Nine USH genes have so far been identified: MYO7A (OMIM 276900 (Weil et al. 1995)), USH1C (OMIM 276904 (Verpy et al. 2000)), CDH23 (OMIM 601067 (Bolz et al. 2001; Bork et al. 2001)), PCDH15 (OMIM 602083 (Ahmed et al. 2001; Alagramam et al. 2001)), USHIG (OMIM 606943 (Weil et al. 2003)) (type I); USH2A (OMIM 276901 (Eudy et al. 1998; Van Wijk et al. 2004)), ADGRVI (OMIM 605472 (Weston et al. 2004)), WHRN (OMIM 611383 (Ebermann et al. 2007)) (type II); and CLRNI (OMIM 276902 (Sankila et al. 1995)) (type III). CIB2 (OMIM 605564) was described to be associated with USH type I but this was later refuted (Booth et al. 2018; Riazuddin et al. 2012). Finally, PDZD7 (OMIM 612971) has been suggested to be a modifier gene of retinal disease and a contributor to digenic USH (Ebermann et al. 2010) and was shown to be causal to non-syndromic hearing loss type DFNB57 (OMIM 618003 (Booth et al. 2015; Vona et al. 2016)).

In 2018, a homozygous missense variant (Supplemental Table 1) in the arylsulfatase G (ARSG) gene (OMIM 610008) was associated with an atypical USH phenotype characterized by late-onset RP with a distinctive retinal phenotype of ring-shaped atrophy along the arcades, late-onset progressive SNHL, and no vestibular involvement (Khateb et al. 2018). Later, when a second homozygous $A R S G$ missense variant was described that caused a similar remarkably late onset of visual and hearing impairment, this phenotype was defined as USH type IV (OMIM 618144) (AbadMorales et al. 2020). The classification as a fourth, distinct USH type was confirmed by the identification of three additional variants associated with similar phenotypic characteristics (Peter et al. 2020). Five other novel ARSG variants were subsequently reported to underlie this newly described phenotype (Fowler et al. 2021; Igelman et al. 2021).

$A R S G$ encodes the sulfatase ARSG, which is transported to lysosomes after biosynthesis in the endoplasmic reticulum (ER) (Ferrante et al. 2002; Kowalewski et al. 2014). ARSG has been shown to hydrolyze pseudosubstrates such as $p$-nitrocatechol sulfate (pNCS) and 4-methylumbelliferyl sulfate (Frese et al. 2008). Moreover, the physiological substrate of ARSG has been determined to be 3-O-sulfated glucosamine in heparan sulfate and ARSG was shown to be critical for the complete lysosomal degradation of 3-O-glucosamine modified heparan sulfate (Kowalewski et al. 2014). The ARSG sulfatase is ubiquitously expressed in mice, including the kidney, testis, liver, spleen, brain, retina, and cochlea (Girotto et al. 2014; Kowalewski et al. 2014; Kowalewski 2015; Kruszewski et al. 2016; Ratzka 2010).

This report confirms both clinically and molecularly that $A R S G$ variants are causal to USH type IV. We describe three novel pathogenic $A R S G$ variants, two novel likely pathogenic variants, and one previously described pathogenic variant in three unrelated individuals. All subjects share a phenotype of late-onset SNHL and RP, characterized by predominantly pericentral and macular changes.

\section{Materials and methods}

For this retrospective case study, clinical and genetic data of included subjects were obtained from the Radboud university medical center (Nijmegen, the Netherlands), the University Medical Center Freiburg (Germany) and the Mater Misercordiae University Hospital (Dublin, Ireland). All included subjects were previously seen at the out-patient clinic of these hospitals.

\section{Clinical evaluation of recruited subjects}

To obtain a complete description of the subjects' phenotypes, we retrospectively collected demographic data and general medical history, ophthalmic data, audiological data, and data on vestibular function. Demographics and medical history included age, descent, comorbidities, medication use, and medical family history. For ophthalmic phenotyping, we collected ocular history, age of onset and progression of ophthalmic symptoms, best corrected visual acuity, refractive error, slit lamp examination findings, and multimodal imaging including color fundus photography, optical coherence tomography (OCT), visual field tests, electroretinography (ERG), and fundus autofluorescence. Audiological data included age of onset, type and progression of audiological symptoms, medical history of the ear, otoscopic assessment, pure tone and speech audiometry, and speech-in-noise testing. The medical history of the ear included recurrent ear infections, previous noise exposure, the use of ototoxic medication, meningitis, severe head injuries, and ear surgeries. Finally, we collected data on vestibular function by identifying whether vestibular symptoms were present and whether vestibular function had been examined. Incomplete data were supplemented with additional diagnostics if possible.

\section{Auditory phenotype analyses}

RStudio (version 1.4.1106) was used to analyze and plot the thresholds for pure-tone audiometry. Air conduction thresholds were used to analyze the observed severity and degree of symmetry of hearing loss and audiogram configuration. In case of 
an air-bone gap, the bone conduction thresholds of all audiograms of the subject in question were used instead. In addition, age-related typical audiograms (ARTA) were derived from linear regression analysis of all available audiometric data of included and previously reported subjects as described to provide insight into the rate of progression of hearing loss (Huygen et al. 2003). In addition to assessing potential differences in the progression of hearing loss, the age of onset of hearing loss was determined. The annual threshold deterioration was calculated using cross-sectional non-linear regression analyses of hearing thresholds as a function of age. First, the pure-tone average (PTA) across $0.5-4.0 \mathrm{kHz}\left(\mathrm{PTA}_{0.5-4 \mathrm{kHz}}\right)$ for each subject was determined. A two-parameter logistic function was used to fit the data, i.e. $\mathrm{PTA}_{0.5-4 \mathrm{kHz}} \sim \frac{130}{1+e^{\left(- \text {scale }_{*}\left(\text { age-age }_{\text {mid }}\right)\right)}}$, similar to what has been described previously (Pauw et al. 2011). The parameter $a g e_{\text {mid }}$ describes the age at which the hearing thresholds are halfway between $0 \mathrm{~dB}$ and the asymptotic value (fixed at $130 \mathrm{~dB}$ ). The parameter scale represents the slope of the function at this midpoint, which was used as an estimate for the annual threshold deterioration. The calculated age of onset was defined as when the calculated hearing threshold exceeds $25 \mathrm{~dB}$, defined by the $\mathrm{WHO}$ as abnormal hearing, and subjects could benefit from amplification (Informal Working Group on Prevention of Deafness and Hearing Impairment Programme Planning \& World Health Organization 1991). The calculated age of onset was determined by interpolating the function fit using the parameters age $e_{\text {mid }}$ and scale. For comparison, the age of onset of SNHL for USH IIa was calculated the same way based on previously published data (Hartel et al. 2016).

\section{Genetic analyses}

For subject N, exome sequencing with targeted gene panels for vision disorders (version DG-2.13, consisting of 408 genes) and hearing impairment (version DG-2.15 and DG-2.18, consisting of 173 and 208 genes) was performed in the ISO15189 accredited Genome Diagnostic Laboratory of the Radboud university medical center (Nijmegen, the Netherlands) according to routine diagnostic procedures (Haer-Wigman et al. 2017). Variants in genes from these panels with a frequency below $5 \%$ in the dbSNP database and below $1 \%$ in an in-house database (consisting of exome sequencing data of 24,488 individuals mainly of Dutch origin) and within the exon or within the intronic position of -8 to +3 were interpreted and classified based on existing variant classification guidelines established by the Association for Clinical Genetic Science (Plon et al. 2008; Wallis et al. 2013).

Subject D and F were pre-screened to exclude biallelic variants in other USH-associated genes in Trinity College Dublin (Ireland) as part of the Target 5000 study (Whelan et al. 2020) (subject D) and in the University Medical Center Freiburg (Germany) with the 2016 CeGat panel for USH (CeGaT GmbH, Tübingen, Germany) (subject F). The CeGat panel for subject $\mathrm{F}$ was later expanded to include ABCA4 (OMIM 601691), CNGAl (OMIM 123825), EYS (OMIM 612424), PDE6A (OMIM 180071), PDE6B (OMIM 180072), and RPE65 (OMIM 180069).

Genome sequencing was performed for subjects $\mathrm{D}$ and $\mathrm{F}$ as described before, with $2 \times 150$ nt paired-end reads and a minimal median coverage of $30 \times$ (Fadaie et al. 2021). In the analysis of genome sequencing data, single nucleotide variants were first prioritized based on the in-house frequency ( $<1 \%$, database consisting of genome sequencing data of 702 individuals mainly of Dutch origin) and the Genome Aggregation Database (gnomAD) minor allele frequency $(\leq 1 \%)$ (Karczewski et al. 2020). All exonic variants, variants at exon-intron boundaries, and deep-intronic variants in genes associated with USH were considered and ranked based on predicted pathogenicity. All stop-gain variants were considered pathogenic. Missense variants were evaluated using the following prediction tools and threshold scores: CADD_PHRED $(\geq 15)$ (Kircher et al. 2014), PhyloP $(\geq 2.7)$ (Pollard et al. 2010), Grantham ( $\geq 80$ ) (Grantham 1974), SIFT (Ng and Henikoff 2001), and MutationTaster (Schwarz et al. 2014). Potential effects on splicing were evaluated by employing SpliceAI ( $\geq 0.1 / 1)$ (Jaganathan et al. 2019). Copy number variants (detected with Control-FREEC Copy number and allelic content caller (Boeva et al. 2012)) and structural variants (detected with Manta Structural Variant Caller (Chen et al. 2016)) were prioritized based on whether they passed our in-house quality filter and whether they affected genes known to be associated with USH. All variants were visualized with Integrative Genomics Viewer (version 2.4) to confirm their presence.

When DNA of relatives was available or variants were in close proximity to each other, the presence of variants in trans was determined by PCR and subsequent Sanger sequencing according to standard protocols.

\section{Functional analyses of identified variants}

Immunoblot and sulfatase activity assays were performed as previously described (Khateb et al. 2018; Peter et al. 2020). Therefore, cDNA expression vectors coding for C-terminally 3xFLAG-tagged wildtype (WT) and mutated ARSG were generated by PCR and cloning into the pcDNA4/TO-C$3 x$ Flag vector with $E c o R 1$ and $X h o I$ followed by transfection and selection of stable cell lines (primer sequences are provided in Supplemental Table 2). Both patient-derived missense variants were introduced by site-directed mutagenesis as previously described in the WT ARSG (Zheng et al. 2004) (primer sequences are provided in Supplemental Table 2). All constructs were sequence-validated by Sanger 
sequencing. Subsequently, HT1080 cells were transfected as previously described (Peter et al. 2020). HT1080 cells were treated with $600 \mu \mathrm{g} / \mathrm{ml}$ Zeocin (Invivogen, San Diego, CA, USA) three days after transfection, and stable cell lines were used for immunoblotting and activity assays after reaching confluence and passaging in Zeocin-containing selection medium after two passages. Immunoblotting of transfected HT1080 cells was performed according to standard procedures with a nitrocellulose membrane and antibodies against the FLAG-tag (mouse monoclonal, clone M2; Sigma Aldrich, St. Louis, MO, USA), as well as glyceraldehyde 3-phosphate dehydrogenase (rabbit polyclonal, SC-335; Santa Cruz Biotechnology, Dallas, TX, USA). Sulfatase activity was measured photometrically by the turnover of pNCS from protein lysates of stable HT1080 cell lines with the WT ARSG construct or the construct harboring an $A R S G$ variant.

Minigene splice assays were performed for variants with a predicted effect on splicing. The genomic regions of interest, including the exon and 500nt intron sequence at both ends, were amplified from patient DNA with PCR (primer sequences are provided in Supplemental Table 2). The PCR product was then inserted in a pCI-NEO vector, adapted to the Gateway ${ }^{\circledR}$ cloning system as previously described (Sangermano et al. 2016). The vector inserts were verified by Sanger sequencing. WT and mutant constructs (500 ng) were subsequently transfected individually into HEK293T cells using polyethylenimine $(100 \mu \mathrm{g} / \mathrm{ml}$ in $150 \mathrm{mM} \mathrm{NaCl})$. Approximately $24 \mathrm{~h}$ post-transfection, RNA was isolated by employing the NucleoSpin RNA Clean-up Kit (Macherey-Nagel, Düren, Germany). 500 ng of RNA was used for cDNA synthesis with the iScript cDNA synthesis kit (Bio-Rad, Hercules, CA, USA), following the manufacturer's instructions. The cDNA derived from the vector insert was amplified with primers for RHO exons 3 and 5 and amplicons were screened with Sanger sequencing. A PCR for $G A P D H$ was performed as cell lysis control.

\section{Results}

\section{Clinical evaluation of recruited subjects}

Subject N is a 51-year-old Dutch man of Turkish descent seen at the Radboud university medical center in Nijmegen, the Netherlands. His medical history was uneventful, besides hypothyroidism and occupational noise exposure for many years. In particular, there was no relevant ophthalmic history nor any family history related to hearing or vision loss. His parents were not known to be consanguineous. He experienced peripheral vision loss and night blindness since the age of 46 and was diagnosed with RP aged 49 (Supplemental Table 3). His visual acuity was relatively spared (OD (right eye) 20/25 and OS (left eye) 20/32 Snellen). Ophthalmoscopy revealed waxy pallor of the optic disc, mild attenuation of the vessels, and a preserved fovea with perifoveal retinal pigment epithelial mottling. Atrophy was present around the vascular arcades; adjacent to the atrophy, predominantly located nasally and superior to the optic disc, intraretinal bone spicules were noted (Supplemental Fig. 1). The far periphery appeared relatively preserved. OCTs showed foveal sparing with only paracentral loss of the outer retina, corresponding to the relatively mild loss of visual acuity. On fundus autofluorescence, a ring of hyperautofluorescence was visible in the posterior pole at the transition zone. The mid-periphery showed confluent areas of hypoautofluorescence with preserved autofluorescence in the far periphery. ERG revealed lower scotopic than photopic responses; both were diminished. Goldmann perimetry showed an absolute ring scotoma with intact central vision and a relatively preserved peripheral field in accordance with a normal V-4e Isopter. At the age of 42 , before his RP diagnosis, subject $\mathrm{N}$ was diagnosed with bilateral SNHL for which he is rehabilitated with bilateral conventional hearing aids (Supplemental Table 4). In addition, he experienced tinnitus. Physical examination and otoscopy showed no abnormalities. Pure tone audiometry revealed bilateral moderate to severe SNHL, with air and bone conduction PTAs $(0.5-4.0 \mathrm{kHz})$ of 49 and $46 \mathrm{~dB}$ hearing level (dB HL) (right) and 55 and $53 \mathrm{~dB} \mathrm{HL}$ (left) at age 46. At age 49, there was asymmetry in the air conduction thresholds, mainly in the high frequencies to the detriment of the right. An air-bone gap was observed primarily in the right ear, which could not be explained by otoscopy or CT. The latter revealed no congenital temporal bone abnormalities. At that time, air and bone conduction PTAs were 70 and $51 \mathrm{~dB} \mathrm{HL}$ (right) and 64 and $55 \mathrm{~dB} \mathrm{HL}$ (left). Based on the bone conduction PTAs, the progression in three years was 5 (right) and $3 \mathrm{~dB}$ HL (left). The subject did not report any vestibular problems.

Subject $\mathrm{F}$ is a 72-year-old woman of Caucasian origin, recruited at the Eye Center of the University of Freiburg, Germany. She was diagnosed with hypothyroidism earlier in life. There was no relevant medical or family history related to hearing, vision, or vestibular function. Her parents were not known to be consanguineous. This individual experienced central vision loss from the age of 40 (Supplemental Table 3). Visual acuity deteriorated to hand movement vision only. Ophthalmoscopy revealed a pale optic disc, mild attenuation of the vessels, and atrophy around the arcades with intraretinal bone spicules predominantly located nasally and superior to the atrophy. The far periphery appeared intact. OCT showed complete loss of the outer retinal layers. Fundus autofluorescence showed extensive hypoautofluorescence in the periphery that extended to the inner part of the vascular arcades, leaving a small ring of relative normal autofluorescence in the posterior pole. ERG 
revealed absence of both cone and rod responses. As the disease progressed, concentric restriction of the peripheral visual field and a central scotoma developed. Subject $\mathrm{F}$ also experienced progressive, bilateral SNHL since the age of 20 for which she has been using bilateral conventional hearing aids since age 31-40 (Supplemental Table 4). At the age of 60 and 72, pure-tone audiometry showed moderate to severe SNHL with a flat audiogram configuration and PTAs of $73 \mathrm{~dB}$ HL (both ears) and 90 (right) and $85 \mathrm{~dB}$ HL (left). There were no additional problems, notably no reported vestibular symptoms. Bilateral bithermal vestibular caloric stimulation revealed a symmetrical response of the lateral semicircular canals.

Subject D is an 87-year-old man of Caucasian origin seen at the Mater Misercordiae University Hospital in Dublin, Ireland. He had pulmonary tuberculosis when he was 19 years old. Later in life, he developed gastro-esophageal reflux disease, atrial fibrillation, and benign prostatic hyperplasia. This subject was diagnosed with exotropia of the left eye in his early youth. When he was over 60 years old, a posterior subcapsular cataract was observed bilaterally. Medical and family history was uneventful, his parents were not known to be consanguineous. At the age of 51-60, he experienced night blindness and photophobia (Supplemental Table 3). Over time, visual acuity deteriorated to light perception in the right eye and no-light perception in the left eye at age 86 . Retinal imaging revealed excavation of the nerve heads, mild attenuation of the vessels, and central atrophy connecting to atrophy around the vascular arcades. This was surrounded by a ring of intraretinal bone-spicule hyperpigmentation, nasally and superior to the disc. Fundus autofluorescence showed central hypoautofluorescence and large confluent areas of hypoautofluorescence adjacent and posterior to the vascular arcades. OCT revealed complete loss of outer retinal layers. At the age of 31-40, subject D developed bilateral SNHL for which he was rehabilitated by bilateral conventional hearing aids (Supplemental Table 4). No other audiological data were available or could be obtained. He reported no vestibular symptoms.

Audiograms of the right and left ears of included and previously reported subjects showed a predominantly bilateral moderate to severe high-frequency SNHL (Supplemental Fig. 2). The ARTA displayed an average progression of hearing loss of 1.0-1.5 dB HL per year (Fig. 1). This corresponds with the mean progression of $1.25 \mathrm{~dB}$ HL per year of both included subjects with more than one audiogram available (subjects $\mathrm{N}$ and $\mathrm{F}$ ). The calculated age of SNHL onset was 17 years (Fig. 1).

\section{Identification of ARSG variants}

The genetic analyses of the three described cases revealed six heterozygous $A R S G$ variants (Table 1, Fig. 2).
In subject $\mathrm{N}$, exome sequencing targeting gene panels for vision disorders and hearing impairment initially identified a heterozygous SPP2 (OMIM 602637, isolated RP (Liu et al. 2015)) variant (NM_006944.3:c.439G > A NP_008875.1:p. (Glu147Lys)) and a possibly explanatory heterozygous MCM2 (OMIM 116945, isolated SNHL OMIM 616968 (Gao et al. 2015)) variant (NM_004526.4:c.547C > T NP_004517.2:p.(Arg183Cys)). However, these variants were also identified in unaffected relatives (Supplemental Fig. 3). Re-analysis of the exome sequencing data with an updated gene panel for hearing impairment identified two variants in ARSG: NM_014960.5:c.1212 + 1G > A NP_055775.2:p.(?); NM_014960.5:c.275T > C NP_055775.2:p.(Leu92Pro). Segregation analysis showed that these variants were present in a compound heterozygous state (Supplemental Fig. 3) as there were no unaffected relatives with both $A R S G$ variants. The c. $275 \mathrm{~T}>\mathrm{C}$ p.(Leu92Pro) variant is a missense variant that was predicted to be pathogenic by all used in-silico prediction tools (Table 1). Skipping of exon 10 (out of frame) was predicted to be a consequence of the c. $1212+1 \mathrm{G}>\mathrm{A}$ p.(?) variant (SpliceAI: Donor splice site loss at $-1 \mathrm{nt}(0.99 / 1)$ and acceptor splice site loss at $-121 \mathrm{nt}(0.78 / 1)$ ).

In subject $F$, a heterozygous variant (NM_206933.4:c.6524G > A NP_996816.3:p.(Arg2175His)) was identified in USH2A (OMIM 608400, USH and isolated RP OMIM 613809 (Rivolta et al. 2000)) and genome sequencing was performed to identify a second causal variant in this gene. However, no second $U S H 2 A$ variant could be identified and therefore variants in other USH-associated genes were addressed. This revealed two $A R S G$ variants: NM_014960.5:c.1326del NP_055775.2:p.(Ser443Alafs*12); NM_014960.5:c.1024C > T NP_055775.2:p.(Arg342Trp). The c.1326del p.(Ser443Alafs*12) variant is a previously described pathogenic stop-gain variant (Peter et al. 2020). The c.1024C $>$ T p.(Arg342Trp) variant is a missense variant that was predicted to be pathogenic by all used in-silico prediction tools (Table 1). In addition, this variant was predicted to result in skipping of exon 9 (out of frame) (SpliceAI: Donor splice site loss at $+67 \mathrm{nt}(0.15 / 1)$ and acceptor splice site loss at $-41 \mathrm{nt}(0.25 / 1))$. Segregation analysis could not be performed because relatives were not available.

Genome sequencing was initiated in subject $\mathrm{D}$ because no variants could be identified in genes associated with USH. Initially, four heterozygous variants in USH-associated genes were identified: a stop-gain variant in $A R S G$ (NM_014960.5:c.588C > A NP_055775.2:p.(Tyr196*)), a non-canonical splice site variant in ADGRV1 (OMIM 602,851, USH, NM_032119.4:c.5525-7C > T NP_115495.3:p.(?)), a missense variant in MYO7A (OMIM 276903, USH and isolated SNHL OMIM 601317 (Liu et al. 1997a, Liu et al. 1997b) and 600060 (Liu et al. 1997a, 1997b; Weil et al. 1997), NM_000260.4:c.905G > A NP_000251.3:p.(Arg302His)), and a deep-intronic variant in PCDH15 (OMIM 605514, USH and 
A

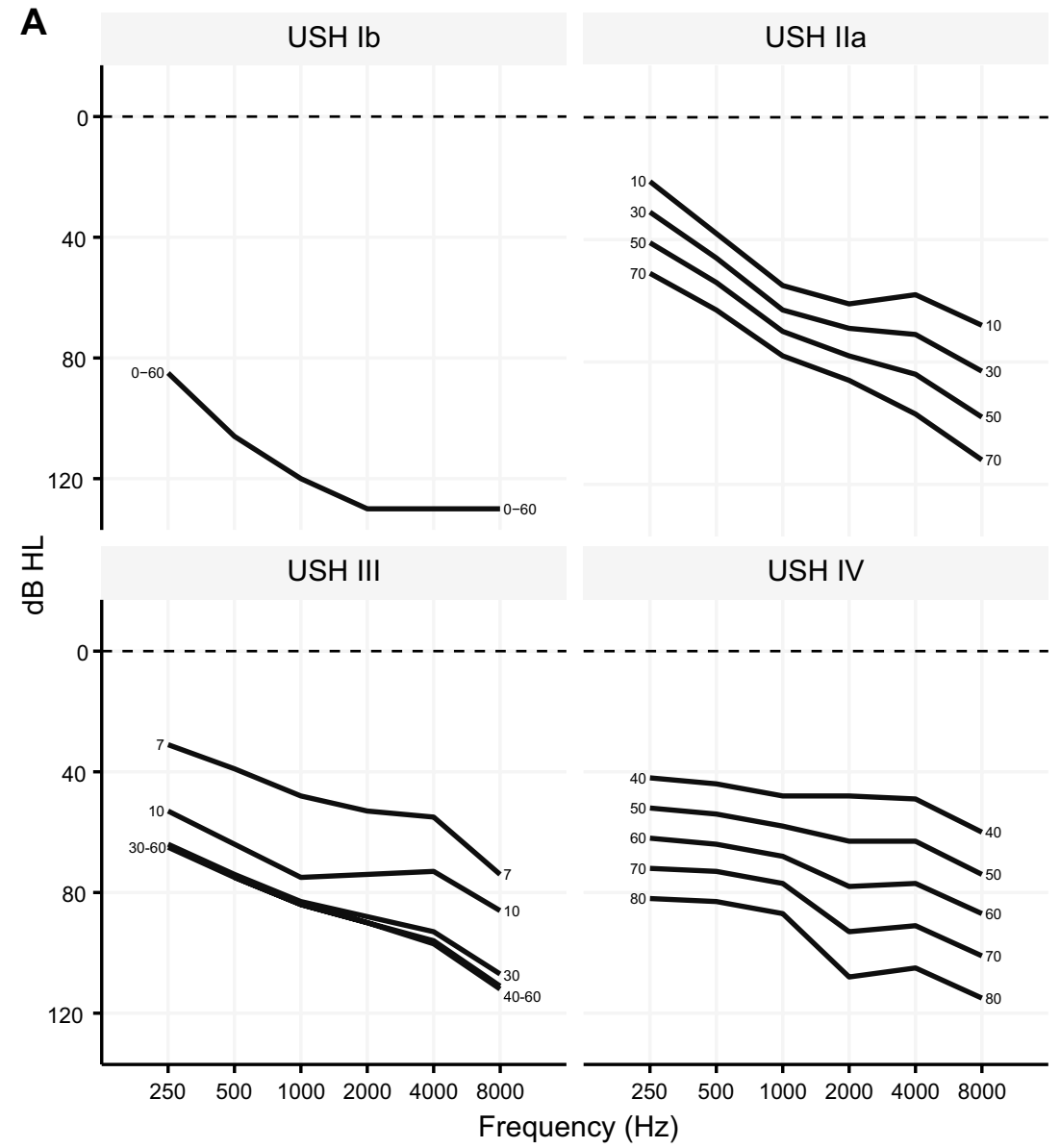

B

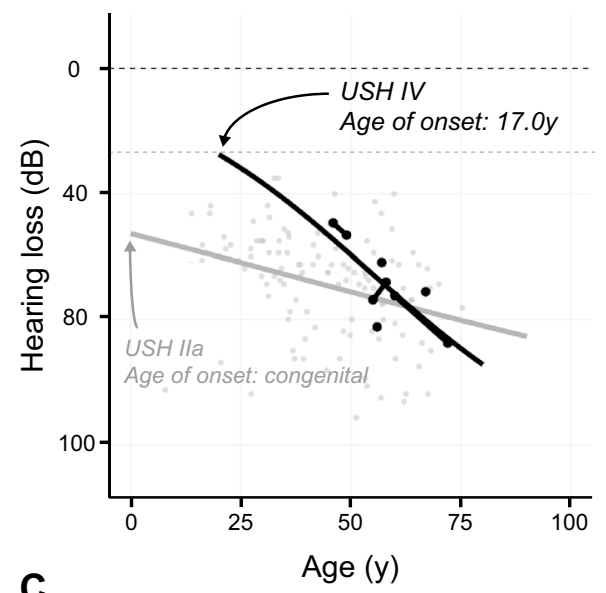

C

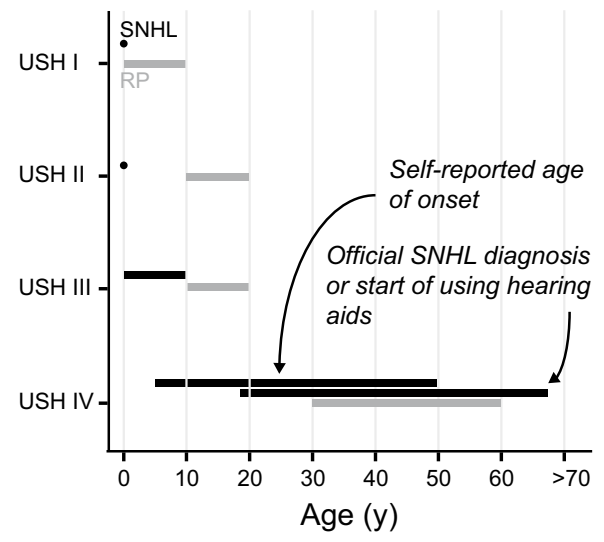

Fig. 1 Audiologic features of USH IV compared to other USH types. A ARTA of USH IV compared to USH Ib (Wagenaar et al. 1999), USH IIa (Hartel et al. 2016), and USH III (Plantinga et al. 2004). Age (in years) is indicated at both ends of all lines. B Calculated age of onset of SNHL for USH IV based on individual PTA PT-4 kHz $_{0.5}$ and compared to USH IIa (Hartel et al. 2016). Black dots represent USH

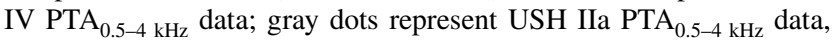

isolated SNHL OMIM 609533 (Ahmed et al. 2003), NM_00 1142764.2:c.1098+2354G > A NP_001136236.1:p.(?)). The in-silico predictions for the missense variant in MYO7A were moderate (CADD_PHRED: 24.5 (threshold: 15), PhyloP: 2.5 (threshold: 2.7), Grantham: 29 (threshold: 80), MutationTaster: 'Benign' and SIFT: 'Tolerated') and the SpliceAI predictions for the ADGRVI and PCDH15 variants were low (ADGRVI: acceptor splice site loss at +11nt (0.01/1); PCDH15: acceptor splice site gain at $+124 \mathrm{nt}(0.24 / 1)$, acceptor splice site loss at $-54 \mathrm{nt}(0.02 / 1)$, donor splice site gain at $+3 \mathrm{nt}(0.19 / 1))$. Also, SpliceAI predicted no pseudo-exon inclusion for the $P C D H 15$ variant. Therefore, the ARSG variant was considered the strongest candidate in a gene associated with USH. Manual inspection of the sequencing reads (CRAM files) revealed indications for a deletion spanning exons 7 and 8 of ARSG. PCR and Sanger sequencing confirmed the deletion and breakpoints: NM_014960.5:c.705-3940_982+295 connected dots represent longitudinal data when more than one audiogram was available for one subject. C Visualization of age of onset of RP (in gray) and SNHL (in black) of USH IV compared to published data for other USH types (Geng et al. 2017; Millan et al. 2011; Nisenbaum et al. 2021; Tsilou et al. 2002) (Table 2). $d B H L$ decibel hearing level; $R P$ retinitis pigmentosa; $S N H L$ sensorineural hearing loss; $y$ years

2del NP_055775.2:p.(Ser235Argfs*29). PCR with a reverse primer designed to bind nucleotides deleted in the c.7053940_982 + 2952del allele demonstrated that the c.588C > A p.(Tyr196*) variant and the deletion are in trans.

The identified $A R S G$ variants were either not detected or detected at low frequencies $(<0.01 \%)$ in gnomAD (Table 1). The previously described variant (c.1326del p.(Ser443Alafs*12)) was classified as 'pathogenic' in the ClinVar database (Landrum et al. 2020) and according to the American College of Medical Genetics and Genomics (ACMG) Standards and Guidelines and its specifications for hearing loss (Table 1) (Abou Tayoun et al. 2018; Oza et al. 2018; Richards et al. 2015). Three novel variants were classified as 'pathogenic' and two as 'likely pathogenic' according to these guidelines. The identified missense variants affect amino acids within protein domains and that have been highly conserved throughout evolution (Fig. 2) (Mistry et al. 2021). 
Table 1 Overview of $A R S G$ variants of recruited subjects

\begin{tabular}{|c|c|c|c|c|c|c|c|c|c|}
\hline $\begin{array}{l}\text { Variant } \\
\text { GRCh37 (hg19) } \\
\text { NM_014960.5 }\end{array}$ & Effect on RNA & $\begin{array}{l}\text { Effect on } \\
\text { protein } \\
\text { NP_055775.2 }\end{array}$ & $\begin{array}{l}\text { GnomAD } \\
\text { minor allele } \\
\text { frequency } \\
(\%)\end{array}$ & $\begin{array}{l}\text { Variant } \\
\text { classification }^{\mathrm{a}}\end{array}$ & $\begin{array}{l}\text { CADD_ } \\
\text { PHRED }\end{array}$ & $\begin{array}{l}\text { Gran- } \\
\text { tham } \\
\text { score }\end{array}$ & $\begin{array}{l}\text { Muta- } \\
\text { tion } \\
\text { taster }\end{array}$ & $\begin{array}{l}\text { Phy- } \\
\text { loP }\end{array}$ & SIFT \\
\hline \multicolumn{10}{|l|}{ Subject N } \\
\hline $\begin{array}{l}\text { Chr17:g.66391335G >A } \\
\text { c. } 1212+1 \mathrm{G}>\mathrm{A}\end{array}$ & $\begin{array}{l}\text { r.1212_1213in } \\
\mathrm{s}[\mathrm{a} ; 1212+2- \\
1212+13]\end{array}$ & $\begin{array}{l}\text { p.(Val405I- } \\
\text { lefs*41) }\end{array}$ & - & $\begin{array}{l}\text { Pathogenic } \\
\text { (PVS1-S, PS3- } \\
\text { M, PM2, } \\
\text { PM3, PP3, } \\
\text { PP4) }\end{array}$ & 34 & $\mathrm{~N} / \mathrm{a}$ & N/a & 6.163 & N/a \\
\hline $\begin{array}{l}\text { Chr17:g.66339801T }>C \\
\text { c. } 275 \mathrm{~T}>\mathrm{C}\end{array}$ & r. $(275 u>c)$ & p.(Leu92Pro) & $\begin{array}{c}0.000398 / \\
0.008700 \\
\text { (Southern } \\
\text { Europe) }\end{array}$ & $\begin{array}{l}\text { Likely patho- } \\
\text { genic } \\
\text { (PS3-M, PM2, } \\
\text { PM3, PP3, } \\
\text { PP4) }\end{array}$ & 27.5 & 98 & $\begin{array}{l}\text { Disease } \\
\text { caus- } \\
\text { ing }\end{array}$ & 6.704 & $\begin{array}{c}\text { Dele- } \\
\text { teri- } \\
\text { ous }\end{array}$ \\
\hline \multicolumn{10}{|l|}{ Subject F } \\
\hline Chr17:g.66416352del c.1326del & r.(1326del) & $\begin{array}{l}\text { p. (Ser443Ala } \\
\text { fs*12) }\end{array}$ & $\begin{array}{l}0.007781 / \\
0.025860 \\
\text { (Southern } \\
\text { Europe) }\end{array}$ & $\begin{array}{l}\text { Pathogenic } \\
\text { (PVS1, } \\
\text { PS3-M, } \\
\text { PM2-Supp, } \\
\text { PM3-Supp, } \\
\text { PP4) }\end{array}$ & 24.4 & $\mathrm{~N} / \mathrm{a}$ & N/a & N/a & N/a \\
\hline $\begin{array}{l}\text { Chr17:g.66381246C }>\mathrm{T} \\
\quad \text { c. } 1024 \mathrm{C}>\mathrm{T}\end{array}$ & r. $1024 c>u$ & p. $(\operatorname{Arg} 342 \operatorname{Trp})$ & $\begin{array}{l}0.000796 / \\
0.009930 \\
\text { (African/ } \\
\text { African } \\
\text { American } \\
\text { XX) }\end{array}$ & $\begin{array}{l}\text { Likely patho- } \\
\text { genic } \\
\text { (PS3-M, PM2, } \\
\text { PM3-Supp, } \\
\text { PP3, PP4) }\end{array}$ & 32 & 101 & $\begin{array}{l}\text { Disease } \\
\text { caus- } \\
\text { ing }\end{array}$ & 1.654 & $\begin{array}{c}\text { Dele- } \\
\text { teri- } \\
\text { ous }\end{array}$ \\
\hline \multicolumn{10}{|l|}{ Subject D } \\
\hline $\begin{array}{l}\text { Chr17:g. } 66352829 \mathrm{C}>\mathrm{A} \\
\text { c. } 588 \mathrm{C}>\mathrm{A}\end{array}$ & r. $(588 \mathrm{c}>\mathrm{a})$ & p.(Tyr196*) & $\begin{array}{l}0.000396 / \\
0.002370 \\
\text { (North- } \\
\text { western } \\
\text { Europe) }\end{array}$ & $\begin{array}{l}\text { Pathogenic } \\
\text { (PVS1-S, PS3- } \\
\text { M, PM2, } \\
\text { PM3, PP4) }\end{array}$ & 36 & $\mathrm{~N} / \mathrm{a}$ & $\mathrm{N} / \mathrm{a}$ & 1.532 & N/a \\
\hline $\begin{array}{l}\text { Chr17:g.66360749_66369617del } \\
\text { c.705-3940_982+2952del }\end{array}$ & r.(705_982del) & $\begin{array}{l}\text { p.(Ser235Arg } \\
\text { fs*29) }\end{array}$ & - & $\begin{array}{l}\text { Pathogenic } \\
\text { (PVS1-S, PS3- } \\
\text { M, PM2, } \\
\text { PM3, PP4) }\end{array}$ & N/a & $\mathrm{N} / \mathrm{a}$ & N/a & N/a & N/a \\
\hline
\end{tabular}

${ }^{a}$ Variant classification was performed using the American College of Medical Genetics and Genomics Standards and Guidelines (Abou Tayoun et al. 2018; Oza et al. 2018; Richards et al. 2015); CADD_PHRED, Combined Annotation Dependent Depletion, threshold value $\geq 15$ (Kircher et al. 2014); ClinVar database (Landrum et al. 2020); GnomAD, Genome Aggregation Database, total population exome frequency/maximum exome frequency (corresponding population); Grantham score, threshold value $\geq 80$ (Grantham 1974); MutationTaster (Schwarz et al. 2014); PhyloP, threshold value $\geq 2.7$ (Pollard et al. 2010); SIFT, Sorting Intolerant From Tolerant (Ng and Henikoff 2001); N/a, not applicable; -, not present in database

\section{Functional analyses of identified variants}

The minigene splice assay for variant c. $1212+1 \mathrm{G}>\mathrm{A}$ (subject $\mathrm{N})$, showed that the original splice donor site was lost, and that an alternative splice donor site at $+13 \mathrm{nt}$ in intron 10 was used. This resulted in an out of frame elongation of exon 10 and a premature stop codon (r.1212_1213ins[a;1212+2_1212+13] p.(Val405Ilefs*41) (Fig. 3). Stable expression in HT1080 fibrosarcoma cells of a construct bearing the second ARSG variant of subject N (c.275T > C p.(Leu92Pro)), followed by immunoblot analysis, revealed a modestly increased ARSG expression level compared to the WT construct (Fig. 4). An additional
ARSG-specific band was detected for the p.(Leu92Pro) construct migrating at a higher apparent molecular weight. ARSG is extensively post-translationally modified by $\mathrm{N}$-glycosylation and limited proteolysis (Kowalewski et al. 2014) and it could be speculated that the posttranslational modifications of this polypeptide differ, e.g., due retention in the endoplasmic reticulum. Notably, a minor band detected for the WT, most likely representing a proteolytically processed form migrating below the full-length protein, was nearly absent in the lane for the p.(Leu92Pro) construct. Sulfatase activity assays revealed a significant activity increase for the artificial substrate pNCS in cells stably expressing WT ARSG compared to untransfected 
A

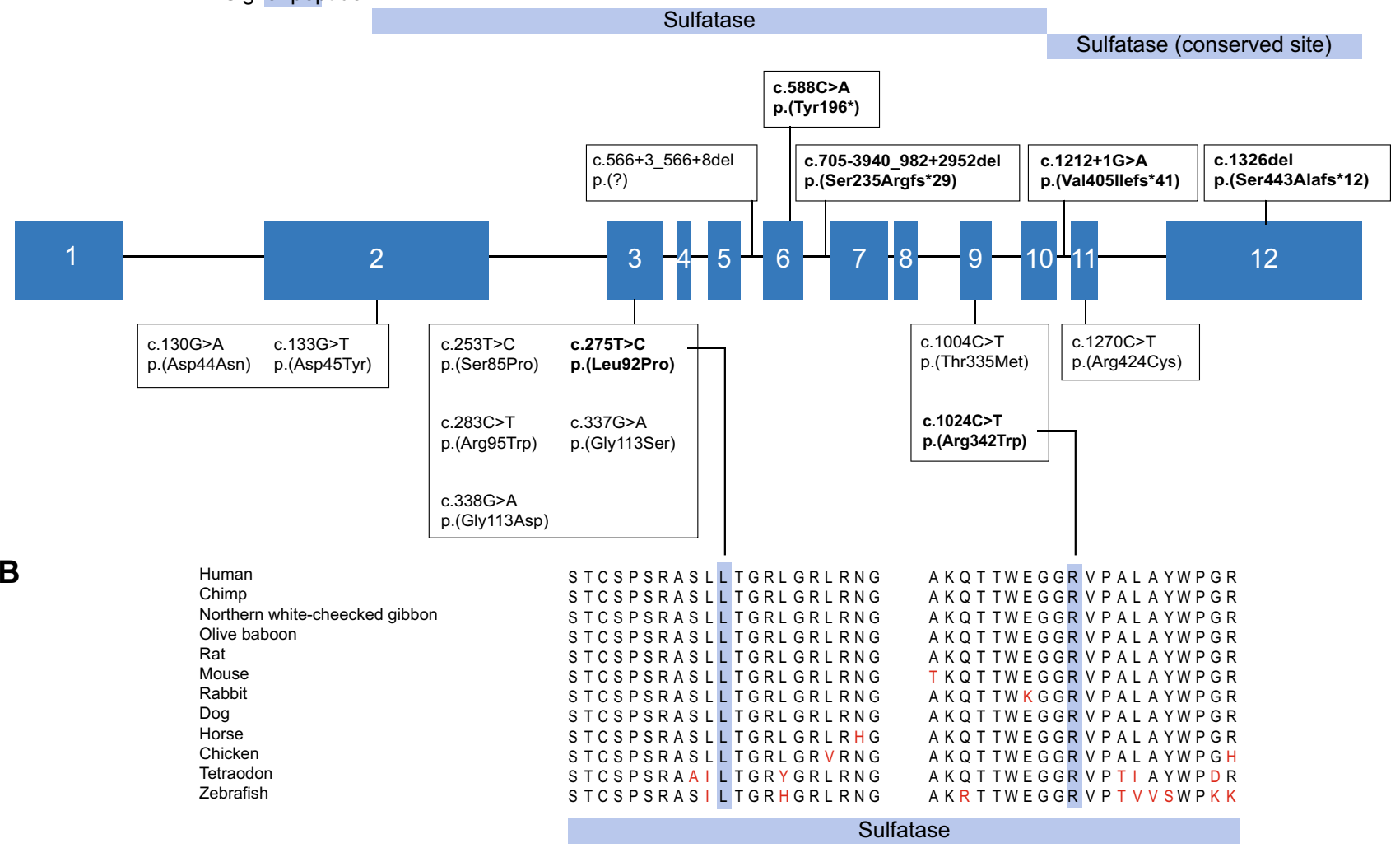

Fig. $2 A R S G$ variants. A Schematic representation of the variability in location and type of novel and previously reported $A R S G$ variants. The twelve $A R S G$ exons are shown in dark blue squares. Protein domains are shown in light blue bars (Mistry et al. 2021). Variants that were identified in the present study are shown in bold. Truncating variants are presented above the exons, missense variants below. B Multiple sequence alignments of the sequence regions contain-

cells. There was also a minimal increase in total sulfatase activity observed in cells expressing the p.(Leu92Pro) construct variant compared to untransfected cells, which, however, can likely be explained by the slightly higher expression (Fig. 4). This analysis indicates that the amino acid substitution presumably results in a nearly complete loss of enzyme activity.

Constructs encoding the truncated c.1326del p.(Ser443Alafs*12) ARSG (subject F) previously revealed similar ARSG expression levels as found in constructs encoding WT ARSG, but with a slightly lower molecular weight, in line with a truncated protein. Also, a significantly lower sulfatase activity was observed than for WT ARSG (Peter et al. 2020). These findings are confirmed in the present study in which we also found similar expression levels of the mutant construct as compared to WT ARSG with a slightly lower molecular weight, as well as significantly lower sulfatase activity in cells expressing the p.(Ser443Alafs*12) variant than in cells expressing WT ARSG (Fig. 4). Immunoblot analysis of ARSG with the amino acid substitution c.1024C $>\mathrm{T}$ p. (Arg342Trp) revealed that the protein is expressed at similar levels when compared ing the two novel missense variants in 12 orthologs (Alamut Visual v.2.13). One-letter amino acid abbreviations are presented. Amino acids that do not correspond with the most conserved amino acid at their position are shown in red. The position of the variants are highlighted in blue. Both variants are located within the sulfatase protein domain

to WT ARSG. Also, sulfatase activity showed no increase in the cells expressing the mutant ARSG compared to untransfected cells, indicating a complete loss of enzyme activity of the mutant ARSG. The minigene splice assay for this latter variant $(\mathrm{c} .1024 \mathrm{C}>\mathrm{T})$ revealed no effect on splicing $(\mathrm{r} .1024 \mathrm{c}>\mathrm{u}$ p.(Arg342Trp)) (Fig. 3).

Finally, immunoblot analysis of the two truncated ARSG proteins c.588C > A p. (Tyr196*) and c.7053940_982+2952del p.(Ser235Argfs*29) identified in subject D confirmed the truncated proteins to be of lower molecular weight than the WT ARSG, within their respective expected ranges (Fig. 4). Slightly lower signal intensities were observed for both mutant constructs compared to the WT construct, indicating lower expression levels of the mutant ARSG proteins. High-molecular weight bands were observed for both mutant constructs, indicating possibly SDS-resistant dimers of the truncated proteins. Determination of the sulfatase activity of cells expressing either mutant ARSG showed no increase of pNCS turnover compared to untransfected cells, indicating a complete loss of enzyme activity. 


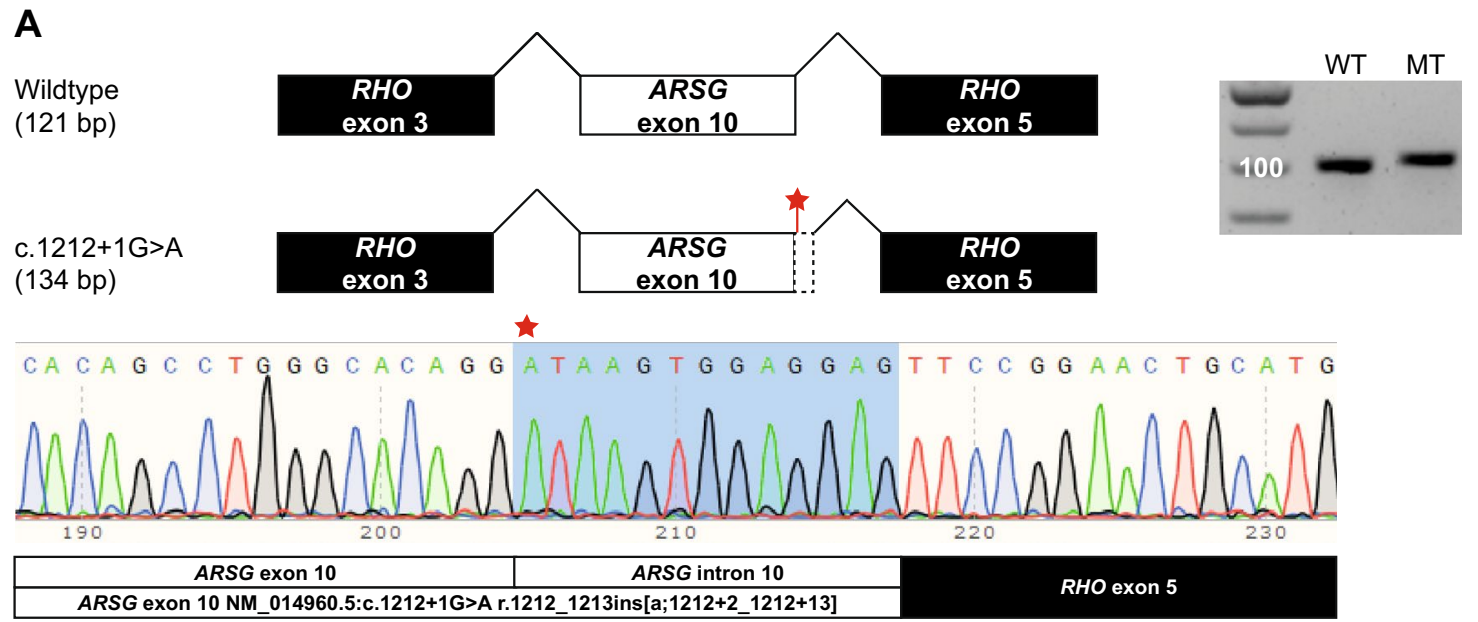

B

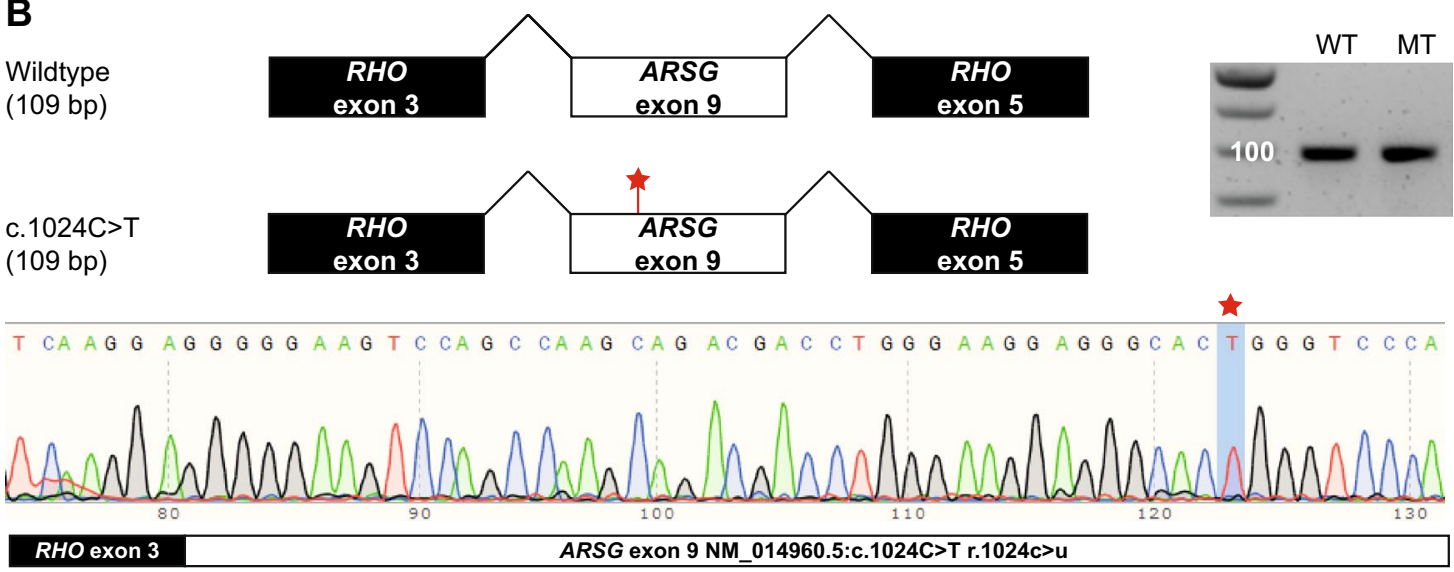

Fig. 3 Results of minigene splice assays for ARSG variants c. $1212+1 \mathrm{G}>\mathrm{A}$ and c. $1024 \mathrm{C}>\mathrm{T}$. In vitro splice assays were performed in HEK293T cells to validate the predicted splice defects. A A canonical splice site variant $(\mathrm{c} .1212+1 \mathrm{G}>\mathrm{A})$ was detected in $A R S G$ (subject $\mathrm{N}$ ) and was predicted by SpliceAI to cause skipping of exon 10 due to a donor splice site loss at -1 nt $(0.99 / 1)$ and acceptor splice site loss at $-121 \mathrm{nt}(0.78 / 1)$. A minigene splice assay revealed the use of an alternative splice donor site at $+13 \mathrm{nt}$ in intron 10 which leads to an out of frame elongation of exon

\section{Discussion}

The present study confirms the recent introduction of USH type IV as being distinctive from the other three types of USH. We describe three subjects with an USH type IV phenotype caused by $A R S G$ variants. This phenotype consists of late-onset RP and late-onset progressive SNHL. The retinal phenotype is characterized by a specific distribution of atrophy around the arcades, peripherally surrounded by intraretinal bone spicules best appreciated nasally and superior to the disc. There is progressive macular involvement eventually resulting in complete loss of the outer retina. There are no signs of vestibular dysfunction, although accurate testing to entirely exclude vestibular involvement could not be performed. In the three studied subjects, we identified six
10 (NM_014960.5:c.1212+1G > A r.1212_1213ins[a;1212+2 _1212+13] NP_055775.2:p.(Val405Ilefs*41)). B A missense variant $($ c. $1024 \mathrm{C}>\mathrm{T})$ was predicted by SpliceAI to cause skipping of exon 9 due to a donor splice site loss at $+67 \mathrm{nt}(0.15 / 1)$ and acceptor splice site loss at $-41 \mathrm{nt}(0.25 / 1)$. A minigene splice assay did not confirm this and demonstrated no effect on splicing (NM_014960.5:c.1024C $>\mathrm{T} \quad$ r.1024c $>\mathrm{u} \quad$ NP_055775.2:p. (Arg342Trp)). Bp base pair; $W T$ wildtype; $M T$ mutant

$A R S G$ variants: one previously reported pathogenic single nucleotide deletion, three novel pathogenic variants, including the first reported structural $A R S G$ variant, and two novel likely pathogenic missense variants (Table 1 ). Five identified variants were shown to cause loss of enzyme activity, in line with previous research (Khateb et al. 2018; Peter et al. 2020). For one variant, sulfatase was not tested, but this variant (c.1212+1G > A p. (Val405Ilefs*41)) is likely to result in loss of sulfatase activity since it leads to premature protein truncation. This is supported by the observation that the c. $1212+1 \mathrm{G}>$ A p. $($ Val405Ilefs*41) variant occurs 38 amino acids N-terminal of the c.1326del p.(Ser443Alafs*12) variant, for which significantly reduced sulfatase activity was found in the current study (Fig. 4). 

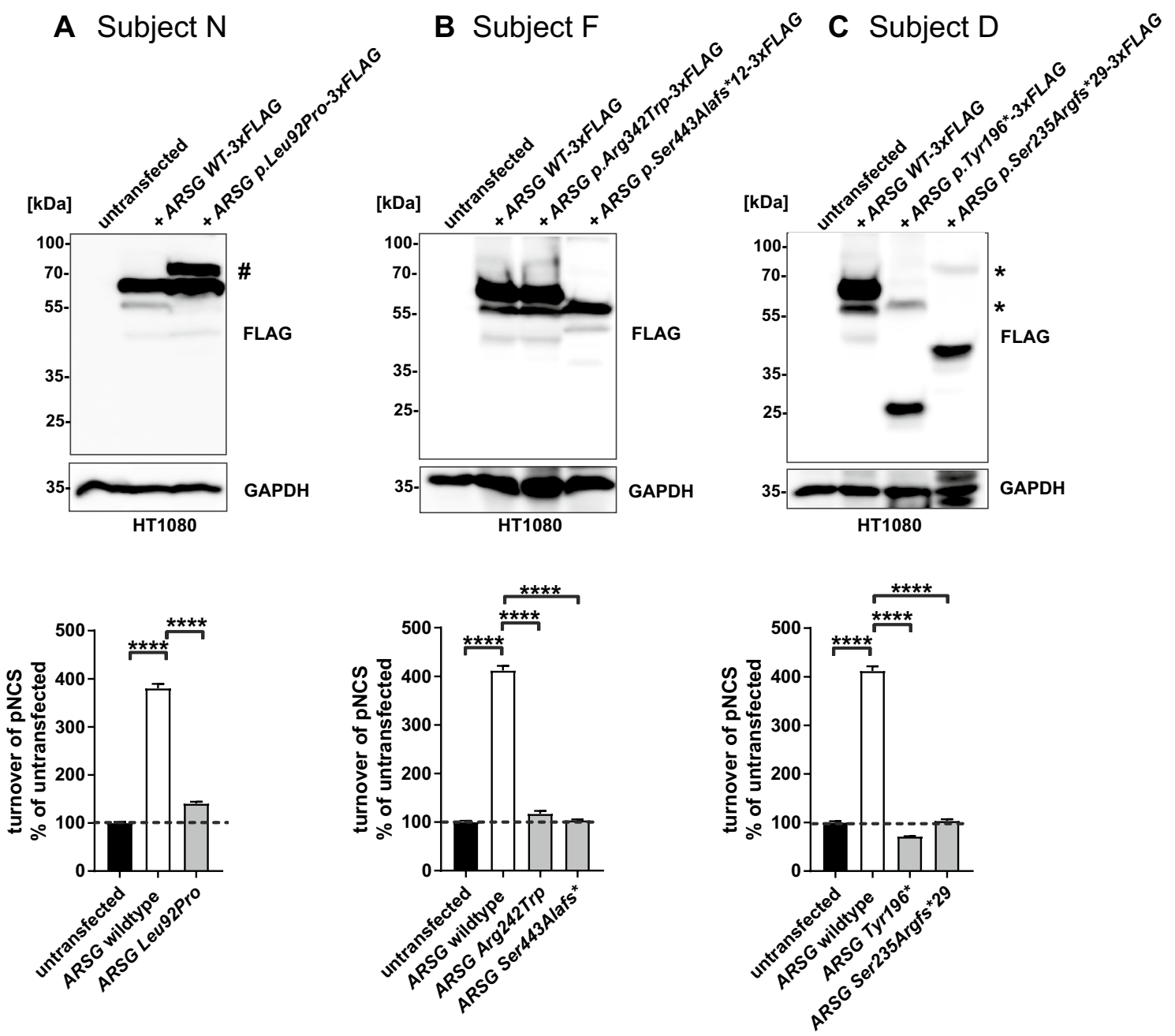

Fig. 4 Functional analysis of $A R S G$ variants identified in subjects N, F, and D. A Subject N: Immunoblot analysis of untransfected or stably transfected HT1080 cells with plasmids coding for 3xFLAGtagged wildtype (WT) ARSG, along with the ARSG variant p.(Leu92Pro). An additional ARSG p.(Leu92Pro)-specific band is labeled with an \#. Other bands in the figure are likely to be caused by limited proteolytic cleavage of ARSG. Total sulfatase activity of cell lysates from untransfected cells, or transfected cells expressing WT ARSG or ARSG with the pathogenic variant p.(Leu92Pro) against the artificial substrate P-nitrocatechol sulfate (pNCS). $N=3$ replicates. Unpaired, two-tailed $t$-test, Mean \pm SEM of the replicates. B Subject F: Immunoblot analysis of untransfected or stably transfected HT1080 cells with plasmids coding for 3xFLAG-tagged WT ARSG, along with the pathogenic variants p.(Arg342trp) and p.(Ser443Alafs*12). Other bands in the figure are likely to be caused by limited proteolytic cleavage of ARSG. Total sulfatase activity of cell lysates from untransfected cells, or from cells

The lysosomal sulfatase ARSG is ubiquitously expressed in mice and has been detected the retina and the cochlea (Girotto et al. 2014; Kruszewski et al. 2016). An Arsg knockout (KO) mouse was shown to accumulate heparan sulfate in enlarged lysosomes and develop typical mucopolysaccharidosis-like features (Kowalewski et al. 2012). An early feature expressing WT ARSG or the pathogenic variants p.(Arg342Trp) and p.(Ser443Alafs*12) against the artificial substrate pNCS. $N=3$ replicates. Unpaired, two-tailed $t$-test, Mean \pm SEM of the replicates. C Subject D: Immunoblot analysis of untransfected or stably transfected HT1080 cells with plasmids coding for 3xFLAG-tagged WT ARSG, along with the pathogenic variants p.(Tyr196*) and p.(Ser235Argfs*29). High-molecular weight bands indicating possibly SDS-resistant dimers of the truncated proteins are labeled with an *. Other bands in the figure are likely to be caused by limited proteolytic cleavage of ARSG. Total sulfatase activity of cell lysates from untransfected cells, or cells expressing WT ARSG or the pathogenic variants p.(Tyr196*) and p.(Ser235Argfs*29) against the artificial substrate pNCS. $N=3$ replicates. Unpaired, two-tailed $t$-test, Mean \pm SEM of the replicates. Antibodies in all panels are against FLAG and GAPDH, used as a loading control. pNCS, P-nitrocatechol sulfate; SEM, standard error of the mean

of the Arsg KO model is progressive photoreceptor degeneration in the retina and dysregulation of various lysosomal proteins, however, with no clear signs of lysosomal storage defects in retinal cells. Generally, these Arsg KO mice present with a milder phenotype than other mouse models of disorders resulting from impaired lysosomal degradation 
of heparan sulfate (Kruszewski et al. 2016). Immunohistochemistry of murine retina revealed ARSG expression in the retinal pigment epithelium (Kruszewski et al. 2016). A homozygous missense loss of function $A R S G$ variant in a canine animal model resulted in sulfatase deficiency and neuronal ceroid lipofuscinosis, however, without affecting the retina (Abitbol et al. 2010). In mouse cochlea, ARSG was demonstrated to be located at the apical side of sensory hair cells in the organ of Corti (Girotto et al. 2014). In human, ARSG mRNA expression levels were the highest in the liver, kidney, pancreas and brain. Retina and cochlea were not included in these analyses (Ferrante et al. 2002; Frese et al. 2008). ARSG is ubiquitously expressed with the highest expression levels in the brain (Carithers et al. 2015; DeLuca et al. 2012; GTEx Consortium 2013, 2020; Melé et al. 2015). A major open question is how variants in $A R S G$ cause USH type IV, and in particular how the impaired degradation of 3-O-modified heparan sulfate is causing cellular dysfunction and cell death despite no apparent lysosomal enlargement. Moreover, it is surprising that none of the patients reported so far show any signs of lysosomal storage defects in peripheral organs or central nervous system (CNS) involvement, as would be expected from the phenotype of the KO mice and ARSG-deficient dogs. Remarkably, a similar situation has been described for other genes causative for lysosomal storage diseases. While variants in genes associated with neuronal ceroid lipofuscinosis (CLN3 (OMIM 607042), CLN5 (OMIM 608102), and $M F S D 8 / C L N 7$ (OMIM611124)) typically lead to severe neuronal dysfunction and lysosomal storage in neurons and the peripheral tissues, some variants present with isolated retina disease (Bauwens et al. 2020; Khan et al. 2017; Ku et al. 2017; Magliyah et al. 2021). Similarly, variants in HGSNAT (OMIM 610453) are associated with mucopolysaccharidosis in the vast majority of patients, but isolated retina degeneration has also been described (Haer-Wigman et al. 2015). One could hypothesize that $A R S G$ variants may also exhibit a broad spectrum of disease as well as isolated retina and cochlear defects. However, the variants we identified are all loss of function variants and lead to phenotypes of RP and SNHL, without neurological symptoms or signs of generalized clinical manifestations of lysosomal storage disease. Therefore, it is not expected that other variants would cause a more broad phenotype.

Comparing the twelve previously described cases supplemented with the presently identified subjects, we observed a fairly similar phenotype (Supplemental Table 3, 4) (AbadMorales et al. 2020; Fowler et al. 2021; Igelman et al. 2021; Khateb et al. 2018; Peter et al. 2020). All individuals were diagnosed with RP with a midlife age of onset (35-60 years), which is later than generally seen in USH type I (first decade) (Tsilou et al. 2002; Van Camp and Smith 2020), type II (first or second decade) (Millan et al. 2011; Tsilou et al.
2002), or type III (variable but usually begins in the second decade) (Nisenbaum et al. 2021) (Fig. 1, Table 2). RP in the identified subjects is characterized by onset at the age of 40-60 years with unique but similar funduscopic changes. Funduscopic abnormalities were primarily seen around the arcades on initial examination. Atrophy was seen mainly around the arcades and extended into the mid-periphery with intraretinal bone-spicule hyperpigmentation adjacent to the atrophic border, most evident nasally and superior to the disc. The far periphery appeared normal. Fundus autofluorescence was consistent with the clinically visible changes and showed a typical pattern of hypoautofluorescence in the mid-periphery but with normal fundus autofluorescence in the far periphery. With age, the macula became more involved, resulting in complete loss of the outer retina in the fovea, as seen on OCT, leading to light perception vision. ERGs revealed lower scotopic than photopic responses, but eventually showed complete absence of both types of responses. All subjects identified in the present study and all but one previously described individuals suffered from progressive SNHL with a self-reported onset ranging from childhood to 50 years of age and an official diagnosis or the start of hearing aid use ranging from 18 to 67 years. Based on the PTA data, we calculated an age of onset of 17 years. Presumably, patients do not experience symptoms of their hearing loss until a more significant loss than the WHO cutoff value of $25 \mathrm{~dB}$ HL and thus have their hearing tested at a later age (Informal Working Group on Prevention of Deafness and Hearing Impairment Programme Planning \& World Health Organization 1991). One individual reported no symptoms of SNHL. However, since no audiometric examination had been performed at his last visit at the age of 48 , it could be that he was not yet aware of the possibly increased hearing thresholds or that this will manifest later in life (Igelman et al. 2021). The reported and calculated age of onset is obviously later than for USH types I and II (congenital), but also later than for type III with an age of onset of SNHL usually in the first decade of life (Fig. 1, Table 2) (Geng et al. 2017). Although, due to the limited age range of the subjects, we could only determine the age of onset of SNHL for USH type IV by interpolating the data. When comparing the USH IV ARTA with that of USH type Ib (Wagenaar et al. 1999), IIa (Hartel et al. 2016), and III (Plantinga et al. 2004) (Fig. 1), the difference in the severity of SNHL with USH $\mathrm{Ib}$ and the higher rate of progression compared to USH IIa are also notable.

It is noteworthy that two subjects ( $\mathrm{N}$ and $\mathrm{F}$ ) had a medical history of hypothyroidism, which was not reported in previous $A R S G$ cases. Identification of larger numbers of USH type IV cases may answer the question on whether hypothyroidism is associated with $A R S G$ defects.

Recent USH type IV reports expand the information on the variability of USH phenotypes. This aids in accurate 
Table 2 Suggested extension of clinical classification of Usher syndrome

\begin{tabular}{|c|c|c|c|}
\hline & Hearing impairment & Visual impairment & Vestibular impairment \\
\hline USH I & $\begin{array}{l}\text { Congenital (Nisenbaum et al. 2021) } \\
\text { Severe to profound (Nisenbaum et al. 2021) } \\
\text { Stable }\end{array}$ & $\begin{array}{l}\text { RP onset in first decade of life (Nisenbaum } \\
\text { et al. 2021) } \\
\text { Mean age of perceived night blindness: 10y } \\
\text { (SD: 6.6) (Tsilou et al. 2002) }\end{array}$ & Severe (Nisenbaum et al. 2021) \\
\hline USH II & $\begin{array}{l}\text { Congenital (Nisenbaum et al. 2021) } \\
\text { Moderate to severe (Nisenbaum et al. 2021) } \\
\text { Variable progression (Stemerdink et al. } \\
\text { 2021) }\end{array}$ & $\begin{array}{l}\text { RP onset in second decade of life or later } \\
\text { (Millan et al. 2011) } \\
\text { Mean age of perceived night blindness: 15y } \\
\text { (SD: 6.9) (Tsilou et al. 2002) }\end{array}$ & Uncertain (Stemerdink et al. 2021) \\
\hline USH III & $\begin{array}{l}\text { Variable age of onset, usually in first decade } \\
\text { of life, range: childhood-35y (Geng et al. } \\
\text { 2017) } \\
\text { Progressive (Nisenbaum et al. 2021) }\end{array}$ & $\begin{array}{l}\text { Variable RP onset, typically begin by sec- } \\
\text { ond decade of life (Nisenbaum et al. 2021) }\end{array}$ & Variable (Nisenbaum et al. 2021) \\
\hline USH IV & $\begin{array}{l}\text { Range of self-reported age of onset: } \\
\text { childhood-50y } \\
\text { Range of official SNHL diagnosis or start of } \\
\text { using hearing aids: } 18-67 \mathrm{y} \\
\text { Moderate to severe }\end{array}$ & Range of RP onset: $30-60 y$ & Uncertain (no patient-reported symptoms) \\
\hline
\end{tabular}

Classification of USH type I-III based on the original classification (Smith et al. 1994; Davenport and Omenn 1977), modified and expanded in response to recent findings. $y$ years

patient counseling, a recurring challenge when patients are diagnosed with newly found or rarely described genotypes. In the literature, this considerable variability is evident in several reports of atypical USH phenotypes. First, some genes may be causative for both USH and isolated deafness or RP, for example CDH23 (OMIM 605516, USH and isolated SNHL OMIM 601386 (Bork et al. 2001)). For that matter, there is no evidence of $A R S G$ to be associated with non-syndromic RP or SNHL, neither in our in-house database (containing exome sequencing data of 2086 individuals analyzed for vision disorders and 2300 individuals analyzed for hearing impairment) nor in the literature to the best of our knowledge. Second, there are cases with variants in known USH-associated genes and phenotypes that differ from the corresponding type of USH, such as an USH II phenotype caused by $\mathrm{CDH} 23$ variants or a phenotype with vestibular dysfunction caused by $U S H 2 A$ variants (Liu et al. 1999; Valero et al. 2019).

In conclusion, our observations confirm the newly described USH type IV caused by $A R S G$ variants (Table 2). This type differs from the other USH types in the late onset of RP and SNHL. The retinal phenotype is characterized by a specific distribution of atrophy around the arcades, peripherally surrounded by intraretinal bone spicules best appreciated nasally and superior to the optic disc. There is progressive macular involvement, eventually resulting in complete loss of the central outer retina. Contrary to atypical USH, which we believe is an aberrant phenotype that results from variants in one of the previously identified USH genes, the ARSG phenotype is consistent and distinct from the original USH types I,
II, and III. This study contributes to the determination of genotype-phenotype associations that are important not only for patient counseling, but also given the development of therapeutic strategies.

Supplementary Information The online version contains supplementary material available at https://doi.org/10.1007/s00439-022-02441-0.

Acknowledgements We acknowledge Dr. Jordi Corominas Galbany, Dr. Galuh DN Astuti, and Prof. Dr. Christian Gilissen for the provision of infrastructure and bioinformatic expert input. Also, we thank Prof. Dr. Caroline Klaver for her contribution to the review and description of the ophthalmic data.

Author contributions HMV, HK, CPL, MD, and RJEP contributed to the conception and design of the study. HMV, JR, CHZL, JW, LP, $\mathrm{CL}, \mathrm{LW}, \mathrm{AD}, \mathrm{JZ}, \mathrm{DJK}$, and GJF were involved in acquisition of data. Analysis and interpretation of the data was performed by HMV, JR, SH, CHZL, SY, JO, JW, LHW, HGY, SR, HK, CPL, MD, and RJEP. All authors were involved in either drafting the manuscript (HMV, JR, CHZL, JO, MD) or in its critical revision.

Funding This study was supported by a grant from the HeinsiusHoubolt foundation (to HK and RJEP), the VELUX Stiftung (to HK and SR), and Fighting Blindness Ireland, the Health Research Board of Ireland, and Health Research Charities Ireland (to GJF).

Data availability statement All data relevant to the study are included in the article or uploaded as supplementary information. The datasets generated and/or analyzed during the current study are available from the corresponding author upon reasonable request.

\section{Declarations}

Conflict of interest The authors have no relevant financial or non-financial interests to disclose. 
Ethics approval Written informed consent for participation and publication was received from all individuals adherent to the tenets of the Declaration of Helsinki, and the study was approved by the local ethics committee of each participating center.

Open Access This article is licensed under a Creative Commons Attribution 4.0 International License, which permits use, sharing, adaptation, distribution and reproduction in any medium or format, as long as you give appropriate credit to the original author(s) and the source, provide a link to the Creative Commons licence, and indicate if changes were made. The images or other third party material in this article are included in the article's Creative Commons licence, unless indicated otherwise in a credit line to the material. If material is not included in the article's Creative Commons licence and your intended use is not permitted by statutory regulation or exceeds the permitted use, you will need to obtain permission directly from the copyright holder. To view a copy of this licence, visit http://creativecommons.org/licenses/by/4.0/.

\section{References}

Abad-Morales V, Navarro R, Bures-Jelstrup A, Pomares E (2020) Identification of a novel homozygous ARSG mutation as the second cause of Usher syndrome type 4. Am J Ophthalmol Case Rep. 19:100736

Abitbol M, Thibaud JL, Olby NJ, Hitte C, Puech JP, Maurer M et al (2010) A canine arylsulfatase G (ARSG) mutation leading to a sulfatase deficiency is associated with neuronal ceroid lipofuscinosis. Proc Natl Acad Sci USA 107(33):14775-14780

Abou Tayoun AN, Pesaran T, DiStefano MT, Oza A, Rehm HL, Biesecker LG et al (2018) Recommendations for interpreting the loss of function PVS1 ACMG/AMP variant criterion. Hum Mutat 39(11):1517-1524

Ahmed ZM, Riazuddin S, Bernstein SL, Ahmed Z, Khan S, Griffith AJ et al (2001) Mutations of the protocadherin gene PCDH15 cause Usher syndrome type 1F. Am J Hum Genet 69(1):25-34

Ahmed ZM, Riazuddin S, Ahmad J, Bernstein SL, Guo Y, Sabar MF et al (2003) PCDH15 is expressed in the neurosensory epithelium of the eye and ear and mutant alleles are responsible for both USH1F and DFNB23. Hum Mol Genet 12(24):3215-3223

Alagramam KN, Yuan H, Kuehn MH, Murcia CL, Wayne S, Srisailpathy CR et al (2001) Mutations in the novel protocadherin PCDH15 cause Usher syndrome type 1F. Hum Mol Genet 10(16):1709-1718

Bauwens M, Storch S, Weisschuh N, Ceuterick-de Groote C, De Rycke R, Guillemyn B et al (2020) Functional characterization of novel MFSD8 pathogenic variants anticipates neurological involvement in juvenile isolated maculopathy. Clin Genet 97(3):426-436

Boeva V, Popova T, Bleakley K, Chiche P, Cappo J, Schleiermacher $G$ et al (2012) Control-FREEC: a tool for assessing copy number and allelic content using next-generation sequencing data. Bioinformatics 28(3):423-425

Bolz H, von Brederlow B, Ramírez A, Bryda EC, Kutsche K, Nothwang HG et al (2001) Mutation of $\mathrm{CDH} 23$, encoding a new member of the cadherin gene family, causes Usher syndrome type 1D. Nat Genet 27(1): 108-112

Booth KT, Azaiez H, Kahrizi K, Simpson AC, Tollefson WT, Sloan $\mathrm{CM}$ et al (2015) PDZD7 and hearing loss: more than just a modifier. Am J Med Genet A 167(12):2957-2965

Booth KT, Kahrizi K, Babanejad M, Daghagh H, Bademci G, Arzhangi $S$ et al (2018) Variants in CIB2 cause DFNB48 and not USH1J. Clin Genet 93(4):812-821
Bork JM, Peters LM, Riazuddin S, Bernstein SL, Ahmed ZM, Ness SL et al (2001) Usher syndrome 1D and nonsyndromic autosomal recessive deafness DFNB12 are caused by allelic mutations of the novel cadherin-like gene CDH23. Am J Hum Genet 68(1):26-37

Boughman JA, Vernon M, Shaver KA (1983) Usher syndrome: definition and estimate of prevalence from two high-risk population. J Chronische Dis 36(8):595-603

Carithers LJ, Ardlie K, Barcus M, Branton PA, Britton A, Buia SA et al (2015) A novel approach to high-quality postmortem tissue procurement: the GTEx project. Biopreserv Biobank 13(5):311-319

Chen X, Schulz-Trieglaff O, Shaw R, Barnes B, Schlesinger F, Källberg $M$ et al (2016) Manta: rapid detection of structural variants and indels for germline and cancer sequencing applications. Bioinformatics 32(8):1220-1222

Davenport SHL, Omenn GS (1977) The heterogeneity of Usher syndrome. In: Fifth international conference on birth defects. Excerpta Medica, Amsterdam, pp 87-88

DeLuca DS, Levin JZ, Sivachenko A, Fennell T, Nazaire MD, Williams C et al (2012) RNA-SeQC: RNA-seq metrics for quality control and process optimization. Bioinformatics 28(11):1530-1532

Ebermann I, Scholl HP, Charbel Issa P, Becirovic E, Lamprecht J, Jurklies B et al (2007) A novel gene for Usher syndrome type 2: mutations in the long isoform of whirlin are associated with retinitis pigmentosa and sensorineural hearing loss. Hum Genet 121(2):203-211

Ebermann I, Phillips JB, Liebau MC, Koenekoop RK, Schermer B, Lopez I et al (2010) PDZD7 is a modifier of retinal disease and a contributor to digenic Usher syndrome. J Clin Invest 120(6):1812-1823

Eudy JD, Weston MD, Yao S, Hoover DM, Rehm HL, Ma-Edmonds $\mathrm{M}$ et al (1998) Mutation of a gene encoding a protein with extracellular matrix motifs in Usher syndrome type IIa. Science 280(5370):1753-1757

Fadaie Z, Whelan L, Dockery A, Li CHZ, van den Born LI, Hoyng $\mathrm{CB}$, et al (2021) BBS1 branchpoint variant is associated with nonsyndromic retinitis pigmentosa. J Med Genet

Ferrante P, Messali S, Meroni G, Ballabio A (2002) Molecular and biochemical characterisation of a novel sulphatase gene: Arylsulfatase G (ARSG). Eur J Hum Genet 10(12):813-818

Fowler NH, El-Rashedy MI, Chishti EA, Vander Kooi CW, Maldonado RS (2021) Multimodal imaging and genetic findings in a case of ARSG-related atypical Usher syndrome. Ophthalmic Genet 42(3):338-343

Frese MA, Schulz S, Dierks T (2008) Arylsulfatase G, a novel lysosomal sulfatase. J Biol Chem 283(17):11388-11395

Gao J, Wang Q, Dong C, Chen S, Qi Y, Liu Y (2015) Whole exome sequencing identified MCM2 as a novel causative gene for autosomal dominant nonsyndromic deafness in a Chinese family. PLoS ONE 10(7):e0133522

Geng R, Omar A, Gopal SR, Chen DH, Stepanyan R, Basch ML et al (2017) Modeling and preventing progressive hearing loss in Usher Syndrome III. Sci Rep 7(1):13480

Girotto G, Vuckovic D, Buniello A, Lorente-Canovas B, Lewis M, Gasparini P et al (2014) Expression and replication studies to identify new candidate genes involved in normal hearing function. PLoS ONE 9(1):e85352

Grantham R (1974) Amino acid difference formula to help explain protein evolution. Science 185(4154):862-864

Grondahl J (1987) Estimation of prognosis and prevalence of retinitis pigmentosa and Usher syndrome in Norway. Clin Genet 31(4):255-264

GTEx Consortium (2013) The genotype-tissue expression (GTEx) project. Nat Genet 45(6):580-585

GTEx Consortium (2020) The GTEx Consortium atlas of genetic regulatory effects across human tissues. Science 369(6509):1318-1330 
Haer-Wigman L, Newman H, Leibu R, Bax NM, Baris HN, Rizel L et al (2015) Non-syndromic retinitis pigmentosa due to mutations in the mucopolysaccharidosis type IIIC gene, heparan-alphaglucosaminide N-acetyltransferase (HGSNAT). Hum Mol Genet 24(13):3742-3751

Haer-Wigman L, van Zelst-Stams WA, Pfundt R, van den Born LI, Klaver CC, Verheij JB et al (2017) Diagnostic exome sequencing in 266 Dutch patients with visual impairment. Eur J Hum Genet 25(5):591-599

Hallgren B (1959) Retinitis pigmentosa combined with congenital deafness: with vestibulo-cerebellar ataxia and mental abnormality in a proportion of cases. Acta Psychiatr Scand Suppl 34(138):1-101

Hartel BP, Löfgren M, Huygen PL, Guchelaar I, Lo ANKN, Sadeghi AM et al (2016) A combination of two truncating mutations in USH2A causes more severe and progressive hearing impairment in Usher syndrome type IIa. Hear Res 339:60-68

Hope CI, Bundey S, Proops D, Fielder AR (1997) Usher syndrome in the city of Birmingham-prevalence and clinical classification. $\mathrm{Br}$ J Opthalmol 81(1):46-53

Huygen PL, Pennings RJ, Cremers CW (2003) Characterizing and distinguishing progressive phenotypes in nonsyndromic autosomal dominant hearing impairment. Audiological Med 1(1):37-46

Igelman AD, Ku C, da Palma MM, Georgiou M, Schiff ER, Lam BL et al (2021) Expanding the clinical phenotype in patients with disease causing variants associated with atypical Usher syndrome. Ophthalmic Genet 42(6):664-673

Informal Working Group on Prevention of Deafness and Hearing Impairment Programme Planning \& World Health Organization (1991) Report of the Informal Working Group on prevention of deafness and hearing impairment programme planning. World Health Organization, Geneva. Available from: https://apps.who. int/iris/handle/10665/58839

Jaganathan K, Kyriazopoulou Panagiotopoulou S, McRae JF, Darbandi SF, Knowles D, Yi Li et al (2019) Predicting splicing from primary sequence with deep learning. Cell 176(3):535-548

Karczewski KJ, Francioli LC, Tiao G, Cummings BB, Alfoldi J, Wang $\mathrm{Q}$ et al (2020) The mutational constraint spectrum quantified from variation in 141,456 humans. Nature 581(7809):434-443

Khan KN, El-Asrag ME, Ku CA, Holder GE, McKibbin M, Arno $\mathrm{G}$ et al (2017) Specific alleles of CLN7/MFSD8, a protein that localizes to photoreceptor synaptic terminals, cause a spectrum of nonsyndromic retinal dystrophy. Invest Ophthalmol vis Sci 58(7):2906-2914

Khateb S, Kowalewski B, Bedoni N, Damme M, Pollack N, Saada A et al (2018) A homozygous founder missense variant in arylsulfatase $\mathrm{G}$ abolishes its enzymatic activity causing atypical Usher syndrome in humans. Genet Med 20(9):1004-1012

Kimberling WJ, Hildebrand MS, Shearer AE, Jensen ML, Halder JA, Trzupek K et al (2010) Frequency of Usher syndrome in two pediatric populations: Implications for genetic screening of deaf and hard of hearing children. Genet Med 12(8):512-516

Kircher M, Witten DM, Jain P, O'Roak BJ, Cooper GM, Shendure J (2014) A general framework for estimating the relative pathogenicity of human genetic variants. Nat Genet 46(3):310-315

Kowalewski B, Lamanna WC, Lawrence R, Damme M, Stroobants S, Padva M et al (2012) Arylsulfatase G inactivation causes loss of heparan sulfate 3-O-sulfatase activity and mucopolysaccharidosis in mice. Proc Natl Acad Sci USA 109(26):10310-10315

Kowalewski B, Lubke T, Kollmann K, Braulke T, Reinheckel T, Dierks T et al (2014) Molecular characterization of arylsulfatase G: expression, processing, glycosylation, transport, and activity. J Biol Chem 289(40):27992-28005

Kruszewski K, Lullmann-Rauch R, Dierks T, Bartsch U, Damme M (2016) Degeneration of photoreceptor cells in arylsulfatase G-deficient mice. Invest Ophthalmol vis Sci 57(3):1120-1131
Ku CA, Hull S, Arno G, Vincent A, Carss K, Kayton R et al (2017) Detailed clinical phenotype and molecular genetic findings in CLN3-associated isolated retinal degeneration. JAMA Ophthalmol 135(7):749-760

Landrum MJ, Chitipiralla S, Brown GR, Chen C, Gu B, Hart J et al (2020) ClinVar: improvements to accessing data. Nucleic Acids Res 48(D1):D835-D844

Liu XZ, Walsh J, Mburu P, Kendrick-Jones J, Cope MJ, Steel KP et al (1997a) Mutations in the myosin VIIA gene cause non-syndromic recessive deafness. Nat Genet 16(2):188-190

Liu XZ, Walsh J, Tamagawa Y, Kitamura K, Nishizawa M, Steel KP et al (1997b) Autosomal dominant non-syndromic deafness caused by a mutation in the myosin VIIA gene. Nat Genet 17(3):268-269

Liu XZ, Hope C, Liang CY, Zou JM, Xu LR, Cole T et al (1999) A mutation (2314delG) in the Usher syndrome type IIA gene: high prevalence and phenotypic variation. Am J Hum Genet 64(4):1221-1225

Liu Y, Chen X, Xu Q, Gao X, Tam PO, Zhao K et al (2015) SPP2 mutations cause autosomal dominant retinitis pigmentosa. Sci Rep 5:14867

Magliulo G, Iannella G, Gagliardi S, Iozzo N, Plateroti R, Mariottini A et al (2017) Usher's syndrome type II: a comparative study of genetic mutations and vestibular system evaluation. Otolaryngol Head Neck Surg 157(5):853-860

Magliyah MS, Geuer S, Alsalamah AK, Lenzner S, Drasdo M, Schatz $P$ (2021) Association of the recurrent rare variant $\mathrm{c} 415 \mathrm{~T}>\mathrm{C}$ pPhe139Leu in CLN5 with a recessively inherited macular dystrophy. JAMA Ophthalmol 139(3):339-343

Melé M, Ferreira PG, Reverter F, DeLuca DS, Monlong J, Sammeth M et al (2015) Human genomics. The human transcriptome across tissues and individuals. Science 348(6235):660-665

Millan JM, Aller E, Jaijo T, Blanco-Kelly F, Gimenez-Pardo A, Ayuso C (2011) An update on the genetics of usher syndrome. J Ophthalmol 2011:417217

Mistry J, Chuguransky S, Williams L, Qureshi M, Salazar GA, Sonnhammer ELL et al (2021) Pfam: the protein families database in 2021. Nucleic Acids Res 49(D1):D412-D419

Ng PC, Henikoff S (2001) Predicting deleterious amino acid substitutions. Genome Res 11(5):863-874

Nisenbaum E, Thielhelm TP, Nourbakhsh A, Yan D, Blanton SH, Shu $Y$ et al (2021) Review of Genotype-Phenotype correlations in Usher syndrome. Ear Hear 43:1-8

Oza AM, DiStefano MT, Hemphill SE, Cushman BJ, Grant AR, Siegert RK et al (2018) Expert specification of the ACMG/AMP variant interpretation guidelines for genetic hearing loss. Hum Mutat 39(11):1593-1613

Pauw RJ, Huygen PL, Colditz GM, Cremers CW (2011) Phenotype analysis of an Australian DFNA9 family with the $1109 \mathrm{~N} \mathrm{COCH}$ mutation. Ann Otol Rhinol Laryngol 120(6):414-421

Peter VG, Quinodoz M, Sadio S, Held S, Rodrigues M, Soares M et al (2020) New clinical and molecular evidence linking mutations in ARSG to Usher syndrome type IV. Hum Mutat 42(3):261-271

Plantinga RF, Kleemola L, Huygen PL, Joensuu T, Sankila EM, Pennings RJ et al (2004) Serial audiometry and speech recognition findings in Finnish Usher syndrome type III patients. Audiol Neurootol 10(2):79-89

Plon SE, Eccles DM, Easton D, Foulkes WD, Genuardi M, Greenblatt MS et al (2008) Sequence variant classification and reporting: recommendations for improving the interpretation of cancer susceptibility genetic test results. Hum Mutat 29(11):1282-1291

Pollard KS, Hubisz MJ, Rosenbloom KR, Siepel A (2010) Detection of nonneutral substitution rates on mammalian phylogenies. Genome Res 20(1):110-121

Riazuddin S, Belyantseva IA, Giese AP, Lee K, Indzhykulian AA, Nandamuri SP et al (2012) Alterations of the CIB2 calcium- and 
integrin-binding protein cause Usher syndrome type $1 \mathrm{~J}$ and nonsyndromic deafness DFNB48. Nat Genet 44(11):1265-1271

Richards S, Aziz N, Bale S, Bick D, Das S, Gastier-Foster J et al (2015) Standards and guidelines for the interpretation of sequence variants: a joint consensus recommendation of the American College of Medical Genetics and Genomics and the Association for Molecular Pathology. Genet Med 17(5):405-424

Rivolta C, Sweklo EA, Berson EL, Dryja TP (2000) Missense mutation in the USH2A gene: association with recessive retinitis pigmentosa without hearing loss. Am J Hum Genet 66(6):1975-1978

Rosenberg T, Haim M, Hauch AM, Parving A (1997) The prevalence of Usher syndrome and other retinal dystrophy-hearing impairment associations. Clin Genet 51(5):314-321

Sangermano R, Bax NM, Bauwens M, van den Born LI, De Baere E, Garanto A et al (2016) Photoreceptor progenitor mRNA analysis reveals exon skipping resulting from the ABCA4 c.5461-10T $\rightarrow C$ mutation in Stargardt disease. Ophthalmology 123(6):1375-1385

Sankila EM, Pakarinen L, Kääriäinen H, Aittomäki K, Karjalainen S, Sistonen $\mathrm{P}$ et al (1995) Assignment of an Usher syndrome type III (USH3) gene to chromosome 3q. Hum Mol Genet 4(1):93-98

Schwarz JM, Cooper DN, Schuelke M, Seelow D (2014) MutationTaster2: mutation prediction for the deep-sequencing age. Nat Methods 11(4):361-362

Smith RJ, Berlin CI, Hejtmancik JF, Keats BJ, Kimberling WJ, Lewis RA et al (1994) Clinical diagnosis of the Usher syndromes. Usher Syndrome Consortium. Am J Med Genet 50(1):32-38

Spandau UH, Rohrschneider K (2002) Prevalence and geographical distribution of Usher syndrome in Germany. Graefes Arch Clin Exp Ophthalmol 240(6):495-498

Stemerdink M, Garcia-Bohorquez B, Schellens R, Garcia-Garcia G, Van Wijk E, Millan JM (2021) Genetics, pathogenesis and therapeutic developments for Usher syndrome type 2. Hum Genet

Tsilou ET, Rubin BI, Caruso RC, Reed GF, Pikus A, Hejtmancik JF et al (2002) Usher syndrome clinical types I and II: could ocular symptoms and signs differentiate between the two types? Acta Ophthalmol Scand 80(2):196-201

Valero R, de Castro-Miro M, Jimenez-Ochoa S, Rodriguez-Ezcurra JJ, Marfany G, Gonzalez-Duarte R (2019) Aberrant splicing events associated to $\mathrm{CDH} 23$ noncanonical splice site mutations in a proband with atypical Usher syndrome 1. Genes (basel) 10(10):732

Van Camp G, Smith RJH (202) Hereditary hearing loss homepage. https://hereditaryhearingloss.org [updated 2020 August 12; cited 2020 November 16]

van Wijk E, Pennings RJ, te Brinke H, Claassen A, Yntema HG, Hoefsloot LH et al (2004) Identification of 51 novel exons of the Usher syndrome type 2A (USH2A) gene that encode multiple conserved functional domains and that are mutated in patients with Usher syndrome type II. Am J Hum Genet 74(4):738-744

Verpy E, Leibovici M, Zwaenepoel I, Liu XZ, Gal A, Salem N et al (2000) A defect in harmonin, a PDZ domain-containing protein expressed in the inner ear sensory hair cells, underlies Usher syndrome type 1C. Nat Genet 26(1):51-55

Vona B, Lechno S, Hofrichter MA, Hopf S, Läig AK, Haaf T et al (2016) Confirmation of PDZD7 as a nonsyndromic hearing loss gene. Ear Hear 37(4):e238-e246

Wafa TT, Faridi R, King KA, Zalewski C, Yousaf R, Schultz JM et al (2021) Vestibular phenotype-genotype correlation in a cohort of 90 patients with Usher syndrome. Clin Genet 99(2):226-235

Wagenaar M, van Aarem A, Huygen P, Pieke-Dahl S, Kimberling W, Cremers C (1999) Hearing impairment related to age in Usher syndrome types $1 \mathrm{~B}$ and $2 \mathrm{~A}$. Arch Otolaryngol Head Neck Surg 125(4):441-445

Wallis Y, Payne S, McAnulty C, Bodmer D, Sister-mans E, Robertson K, et al. (eds) (2013) Practice guidelines for the evaluation of pathogenicity and the reporting of sequence variants in Clinical molecular genetics

Weil D, Blanchard S, Kaplan J, Guilford P, Gibsont F, Walsht J et al (1995) Defective myosin VIIA gene responsible for Usher syndrome type 1B. Nature 374(6517):60-61

Weil D, Küssel P, Blanchard S, Lévy G, Levi-Acobas F, Drira M et al (1997) The autosomal recessive isolated deafness, DFNB2, and the Usher 1B syndrome are allelic defects of the myosin-VIIA gene. Nat Genet 16(2):191-193

Weil D, El-Amraoui A, Masmoudi S, Mustapha M, Kikkawa Y, Laine S et al (2003) Usher syndrome type I G (USH1G) is caused by mutations in the gene encoding SANS, a protein that associates with the USH1C protein, harmonin. Hum Mol Genet 12(5):463-471

Weston MD, Luijendijk MW, Humphrey KD, Moller C, Kimberling WJ (2004) Mutations in the VLGR1 gene implicate G-protein signaling in the pathogenesis of Usher syndrome type II. Am J Hum Genet 74(2):357-366

Whelan L, Dockery A, Wynne N, Zhu J, Stephenson K, Silvestri G et al (2020) Findings from a genotyping study of over 1000 people with inherited retinal disorders in Ireland. Genes (basel) 11(1):105

Zheng L, Baumann U, Reymond JL (2004) An efficient one-step sitedirected and site-saturation mutagenesis protocol. Nucleic Acids Res 32(14):e115

Publisher's Note Springer Nature remains neutral with regard to jurisdictional claims in published maps and institutional affiliations.

\title{
Authors and Affiliations
}

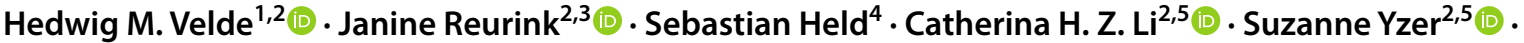 \\ Jaap Oostrik ${ }^{1,2}$ (1) Jack Weeda ${ }^{5} \cdot$ Lonneke Haer-Wigman $^{2,3}$ (1) Helger G. Yntema ${ }^{2,3}$ (1) - Susanne Roosing ${ }^{2,3}$ (1)

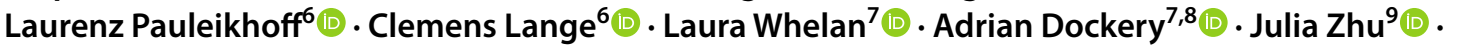

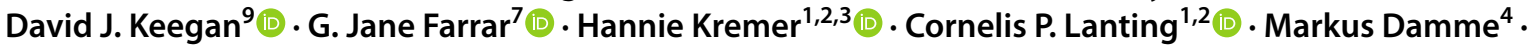 \\ Ronald J. E. Pennings ${ }^{1,2}$ (1)
}

Hedwig M. Velde

Hedwig.Velde@radboudumc.nl

Janine Reurink

Janine.Reurink@radboudumc.nl

Sebastian Held

SHeld@biochem.uni-kiel.de
Catherina H. Z. Li

Catherina.Li@ radboudumc.nl

Suzanne Yzer

Suzanne.Yzer@radboudumc.nl

Jaap Oostrik

Jaap.Oostrik@ radboudumc.nl 
Jack Weeda

Jack.Weeda@ radboudumc.nl

Lonneke Haer-Wigman

Lonneke.Haer-Wigman@ radboudumc.nl

Helger G. Yntema

Helger.IJntema@radboudumc.nl

Susanne Roosing

Susanne.Roosing@ radboudumc.nl

Laurenz Pauleikhoff

Laurenz.Pauleikhoff@uniklinik-freiburg.de

Clemens Lange

Clemens.Lange@uniklinik-freiburg.de

Laura Whelan

Whelanl1@tcd.ie

Adrian Dockery

Dockerya@tcd.ie

Julia Zhu

Julia.Q.Zhu@gmail.com

David J. Keegan

DKeegan@mater.ie

G. Jane Farrar

Jane.Farrar@tcd.ie

Hannie Kremer

Hannie.Kremer@radboudumc.nl
Cornelis P. Lanting

Cris.Lanting@ radboudumc.nl

Markus Damme

MDamme@biochem.uni-kiel.de

1 Hearing and Genes, Department of Otorhinolaryngology, Radboudumc, Nijmegen, The Netherlands

2 Donders Institute for Brain, Cognition and Behaviour, Radboudumc, Nijmegen, The Netherlands

3 Department of Human Genetics, Radboudumc, Nijmegen, The Netherlands

4 Department of Biochemistry, University of Kiel, Kiel, Germany

5 Department of Ophthalmology, Radboudumc, Nijmegen, The Netherlands

6 Eye Center, Medical Center - University of Freiburg, Faculty of Medicine, University of Freiburg, Freiburg, Germany

7 The School of Genetics and Microbiology, Smurfit Institute of Genetics, Trinity College Dublin, Dublin, Ireland

8 Next Generation Sequencing Laboratory, Pathology Department, The Mater Misericordiae University Hospital, Dublin, Ireland

9 Mater Clinical Ophthalmic Genetics Unit, The Mater Misericordiae University Hospital, Dublin, Ireland 